Research Article

\title{
The effect of magnesium sulfate as an adjuvant to $0.5 \%$ bupivacaine on motor and sensory supraclavicular brachial plexus blockade
}

\author{
Lella Nageswara Rao*, V. Jeyalakshmi, M. Nagaraju, S. Anitha
}

Department of Anesthesiology, Katuri Medical College and Hospital, Chinakondrupadu, Guntur, Andhra Pradesh, India

Received: 31 January 2015 Revised: 13 February 2015 Accepted: 07 March 2015

\section{*Correspondence to:}

Dr. Lella Nageswara Rao, Email: nrlella@yahoo.in

Copyright: (C) the author(s), publisher and licensee Medip Academy. This is an openaccess article distributed under the terms of the Creative Commons Attribution NonCommercial License, which permits unrestricted noncommercial use, distribution, and reproduction in any medium, provided the original work is properly cited

\begin{abstract}
Background: Magnesium is a physiologic cation that blocks neuromuscular transmission and does not allow the nerve to be stimulated. This study investigates the effect of adding magnesium sulfate to $0.5 \%$ bupivacaine to extend the duration of sensory and motor blocks of the supraclavicular brachial plexus in orthopedic surgeries of the upper extremities.

Methods: This controlled randomized double-blind study was performed on patients who were candidates for orthopedic surgery of the upper extremities. A total of 60 patients between 18 and 60 years with ASA Class 1 or 2 participated in the study. One Group M received $0.5 \%$ bupivacaine (1.5 mg/kg) with magnesium sulfate $20 \%$ $(3 \mathrm{ml})$ as the case group, while the second Group $\mathrm{P}$ received $0.5 \%$ bupivacaine $(1.5 \mathrm{mg} / \mathrm{kg})$ with normal saline $(3 \mathrm{ml})$ as a placebo to block the supraclavicular brachial plexus using nerve locator. The duration of the sensory and motor block of the supraclavicular brachial plexus was monitored and evaluated using the pinprick and modified Bromage scale.

Results: A total of 60 patients were included in the study with 30 patients having received $0.5 \%$ bupivacaine plus magnesium and the other 30 patients having received $0.5 \%$ bupivacaine plus normal saline. The mean sensory block duration in the case Group M was $249 \pm 9.36$ and in control Group P was $160 \pm 5.62(\mathrm{p}<0.39)$. The mean motor block duration in the case Group M was $232 \pm 9.64$ and in control Group P was $147 \pm 26.52$ (both $\mathrm{p}<0.32$ ). The mean onset of sensory block in case Group $M$ was $15.5 \pm 2.16$ and the onset block in control Group P was 12.73 $\pm 1.18(p<0.49$; statistically not significant). The mean onset of motor block in case Group $\mathrm{M}$ was $23.5 \pm 1.1$ and the onset block in control Group P was $41 \pm 3(\mathrm{p}<0.53$; statistically not significant).

Conclusions: The addition of magnesium sulfate to $0.5 \%$ bupivacaine increased the duration of motor and sensory supraclavicular brachial block in the upper extremities during surgeries when compared to the use of $0.5 \%$ bupivacaine alone, though statistically not significant, but definitely in clinically significant proportions.
\end{abstract}

Keywords: Magnesium sulfate, $0.5 \%$ Bupivacaine, Regional anesthesia

\section{INTRODUCTION}

Regional anesthesia has been accepted as a safe and effective method for various surgical procedures including upper limb surgery. This method can prolong analgesia during surgery and assist with post-operative pain management. A supraclavicular brachial plexus block is commonly used as a regional anesthesia in the hand, arm, and forearm surgeries. Several attempts have been made to prolong the effect of regional anesthetics by sensory and motor blocks of supraclavicular brachial plexus using various factors such as narcotics, verapamil, clonidine, and tramadol. ${ }^{1}$
Magnesium sulfate does not let catecholamines be released from the adrenal and peripheral nerve endings. Therefore, catecholamines receptors are blocked. Hence, magnesium sulfate results are sympathetic blocks. ${ }^{2}$ Some studies have demonstrated that the magnesium seems to reduce the postoperative pain, moreover injecting intravenously led to a reduction of the consumption of anesthetics during surgery. ${ }^{3}$ Studies have also shown that intrathecal administration of magnesium can strengthen the analgesic properties of opioids used for pain management following knee arthroscopy and during childbirth labor. ${ }^{4}$ 


\section{Objectives}

Magnesium may use different mechanisms to prolong the effect of regional anesthetics. Our study was done to evaluate the effect of magnesium sulfate with $0.5 \%$ bupivacaine when used for sensory and motor supraclavicular brachial plexus blocks.

\section{METHODS}

This randomized controlled, double-blind study was done on 60 patients, who were ASA Class 1 or 2 and between the ages of 18 and 60 . The patients were admitted to the Katuri Medical College and Hospital, Guntur, Andhra Pradesh. In addition, they were candidates for hand and forearm surgery. The duration of each surgery was $<90$ mins. Consent was obtained from all patients. The variables of demographic features, onset time of the sensory and motor block, and the duration of sensory and motor block were answered in the questionnaire. The study was approved by the Ethical Committee of Katuri Medical College and Hospital, Guntur, Dr. NTR University of Health Sciences, Andhra Pradesh.

Patients with a history of allergy to the drugs, cardiovascular disorders, hypertension, coagulation abnormalities, excessive bleeding, hemoglobin $<10$, renal failure, local skin infections, opium addiction, pregnancy, or using beta blockers or calcium channel blockers were excluded from the study, as they are risk factors for high-risk operations. It was shown that all blocks were perfect and all patients were suitable candidates for the procedure. Of the 60 patients none were excluded.

Using randomization, 60 medical packets were prepared, mixed, and then given to the nurse in the operating room. Patients eligible to participate in this study and who had given written informed consent were referred to the operating room nurse who distributed one packet to each patient. The patients were introduced to the doctor and the nurse then given each packet. A total of 30 packets, named M, consisted of $0.5 \%$ bupivacaine plus magnesium sulfate and the other 30 packets, named $\mathrm{P}$, consisted of $0.5 \%$ bupivacaine plus normal saline. The nurse gave one of the closed envelopes to each patient and referred them to the doctor. After giving one packet to each patient, the nurse was not allowed to use it again.

Patients were thus randomly allocated into two groups. Group M received magnesium sulfate $(1.5 \mathrm{mg} / \mathrm{kg}$ of $0.5 \%$ bupivacaine plus $3 \mathrm{ml}$ of $20 \%$ magnesium sulfate and diluted in $40 \mathrm{ml}$ of normal saline solution) and Group P (control) received normal saline instead of magnesium sulfate $(1.5 \mathrm{mg} / \mathrm{kg} 0.5 \%$ bupivacaine plus $3 \mathrm{ml}$ of normal saline and diluted in $40 \mathrm{ml}$ of normal saline solution). The dose of magnesium sulfate was calculated based on previous studies. ${ }^{5-7}$ The primary investigator prepared the pharmaceutical components. The anesthesiology resident, who did not know about the pharmaceutical composition, injected the drugs. The method of injection as well as the pinprick test and Bromage test were explained to all patients.

During surgery, electrocardiogram, non-invasive blood pressure, and oxygen saturation level were monitored. The patient's arm on which the operation was performed was adducted and head turned to the contralateral side. Betadine was applied to the site as a topical antiseptic. The patients did not receive any sedatives before the supraclavicular brachial block. After the overlying skin was anesthetized with $1 \mathrm{ml}$ of $2 \%$ xylocaine brachial plexus was located with help of nerve locator with twitch response to the minimum of $0.5 \mathrm{~mA}$ and making sure that no response after injecting the local anesthetic. The supraclavicular brachial plexus block was performed using nerve locator $30 \mathrm{ml}$ of local anesthetic was injected around the nerve sheath. The occasional aspiration and injection was adopted to avoid intravascular injection. The musculocutaneous nerve was blocked by $5 \mathrm{ml}$ of $2 \%$ xylocaine within the body of coracobrachialis muscle. The musculocutaneous nerve that provides sensory input for the lateral forearm also was blocked (in two groups). Sensory block level was monitored at 1-mins intervals, as the onset of the nerve block is rapid. Sensory block level was performed by testing dermatomes of the sensory regions of the radial, median, and ulnar nerves. The intensity of the motor block was assessed using the modified Bromage scale at 1-mins intervals as follows (Table 1).

When the sensory and motor blocks were fully established, the surgery was started. The sensory and motor blocks were assessed by the pinprick test and the modified Bromage test from the initiation of the blocks until the end of anesthesia. Such tests are safe and cause no damage. The end of sensory block was defined by have pain sensation during the pinprick test. At the end of motor block, the patient had pain sensation during the pinprick test in all sensitive areas and the patient had complete movement of their body. All these tests were assessed in the recovery room. The operating time was 90 mins or less and recovery time was approximately 30 mins. After taking the patients to the recovery room, questionnaires of demographic features were completed. The duration of sensory and motor blocks were followed when the patients were in the recovery room. Sensory and motor responsiveness was tested at 10 mins intervals.

Analysis was performed by descriptive statistics, the Chisquare test. Data were analyzed by the SPSS (version 16). A $\mathrm{p}<0.05$ was considered statistically significant.

Table 1: Modified Bromage scale.

\begin{tabular}{|ll|}
\hline 0 & Unable to move fingers \\
\hline 1 & Able to move fingers only \\
\hline 2 & Able to bend the wrist \\
\hline 3 & Full flexion of the elbow \\
\hline
\end{tabular}




\section{RESULTS}

A total of 60 patients were included in the study with 30 patients having received $0.5 \%$ bupivacaine plus magnesium and the other 30 patients having received $0.5 \%$ bupivacaine plus normal saline. There were no significant differences in the demographic data of the patients and differences in the mean age and sex in the two groups were not significant $(p=0.805$ and $p=1)$. All block randomization was done successfully. All the patients were stable based on hemodynamic variables. No patients had complications such as hypotension to control and none were excluded from the study.

The mean sensory block duration in the case group $\mathrm{M}$ was $249 \pm 9.36$ and in control Group P was $160 \pm 5.62$ ( $\mathrm{p}<0.39$; statistically not significant) (Table 2 and Figure 1 ).

The mean motor block duration in the case Group $\mathrm{M}$ was $232 \pm 9.64$ and in the control group was $147 \pm 26.52(p<0.32$; statistically not significant) (Table 3 and Figure 2).

The mean onset of sensory block in case Group M was $15.5 \pm 2.16$ and the onset block in control Group P was $12.73 \pm 1.18$ ( $<0.49$; statistically not significant) (Table 4).

The mean onset of motor block in case Group M was $23.5 \pm 1.1$ and the onset block in control Group P was $41 \pm 3$ $(\mathrm{p}<0.53$; statistically not significant) (Table 5).

Table 2: Duration of sensory block (in minutes).

\begin{tabular}{|lcc|}
\hline Variable & Group M & Group P \\
\hline Mean & 249 & 160 \\
\hline SD & 9.36 & 5.62 \\
\hline
\end{tabular}

$\mathrm{p}<0.39$; statistically not significant, but clinically significant, SD: Standard deviation

Table 3: Duration of motor block (in minutes).

\begin{tabular}{|lcc|}
\hline Variable & Group M & Group P \\
\hline Mean & 232 & 147 \\
\hline SD & 9.64 & 26.52 \\
\hline
\end{tabular}

$\mathrm{p}<0.32$; statistically not significant, but clinically significant, SD: Standard deviation

Table 4: Onset of sensory block (in minutes).

\begin{tabular}{|lcc|}
\hline Variable & Group M & Group P \\
\hline Mean & 15.5 & 12.73 \\
\hline SD & 2.16 & 1.18 \\
\hline
\end{tabular}

$\mathrm{p}<0.49$; statistically not significant, SD: Standard deviation

Table 5: Onset of motor block (in minutes).

\begin{tabular}{|lcc|}
\hline Variable & Group $\mathbf{M}$ & Group P \\
\hline Mean & 23.5 & 41 \\
\hline SD & 1.1 & 3 \\
\hline
\end{tabular}

$\mathrm{p}<0.53$; statistically not significant, SD: Standard deviation

\section{DISCUSSION}

Magnesium is a competitive N-methyl-D-aspartate receptor - receptor antagonist and inhibits the voltagedependent ion channels. In addition, it seems that magnesium sulfate increases the length of the block in intravenous regional anesthesia. ${ }^{8}$ Therefore, improving the quality of local anesthetics in regional and local blocks as well as the management of postoperative acute pain is important for patients who suffer from the pain after surgery such as orthopedic surgery. Various supraclavicular brachial block methods as well as anatomical differences in the nerves of the upper limb warrant further research. This study investigated the effects of adding magnesium sulfate with $0.5 \%$ bupivacaine in supraclavicular brachial plexus blocks to prolong the duration of sensory and motor blockage and diminish postoperative acute pain for the patient.

In this study, the mean duration of the sensory and motor blocks in the $0.5 \%$ bupivacaine plus magnesium Group $\mathrm{M}$ was significantly longer than in the $0.5 \%$ bupivacaine plus normal saline placebo Group $\mathrm{P}$ in clinically significant proportions though not satisfactory. We also assessed the onset of the sensory and motor blocks between the two groups. The onset time of sensory block, i.e. the time from when the injection was completed and the first symptoms of anesthesia in the limb were established, was significantly longer for the $0.5 \%$ bupivacaine plus

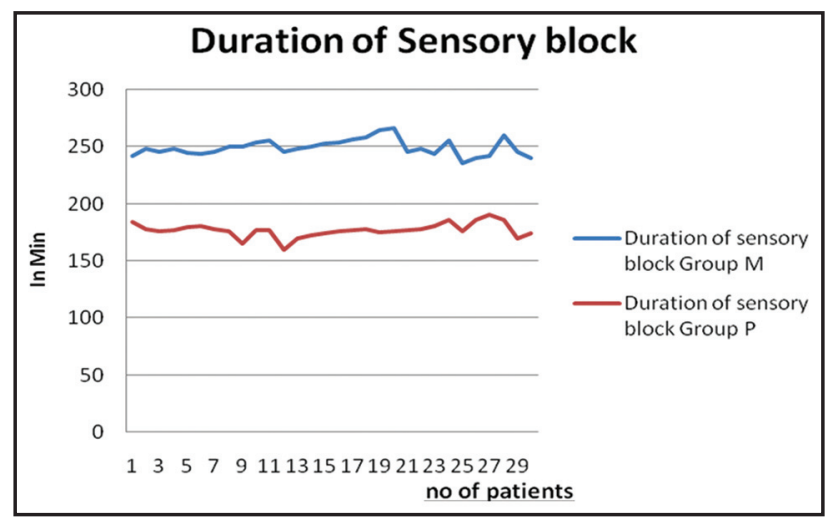

Figure 1: Duration of sensory block.

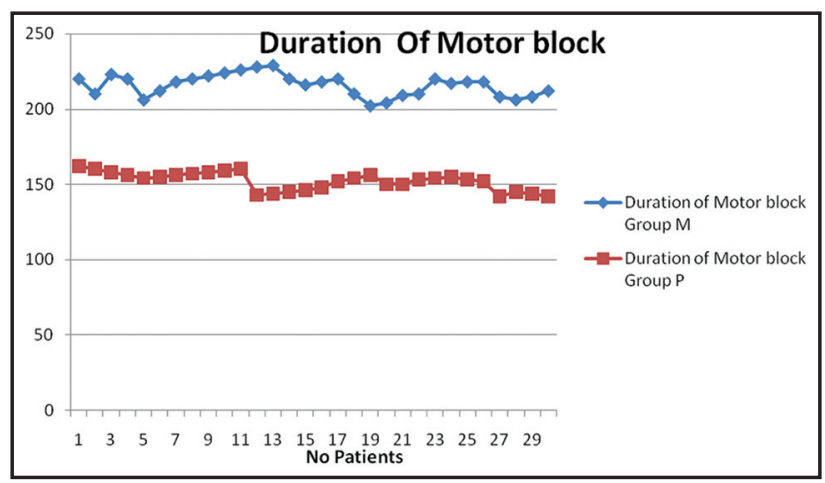

Figure 2: Duration of motor block. 
magnesium group than for the control group who received $0.5 \%$ bupivacaine plus normal saline group. The onset of anesthesia in the motor block also required a longer time in the magnesium plus $0.5 \%$ bupivacaine group when compared with the placebo Group P. However, this difference was statistically not significance. While supraclavicular brachial block using $0.5 \%$ bupivacaine with magnesium sulfate has a delayed onset, the overall duration of the sensory and motor blocks was longer than the controlled condition of $0.5 \%$ bupivacaine with normal saline.

Ozalevli et al. compared intrathecal blocks of bupivacaine with fentanyl and magnesium in combination with sodium chloride in the patients undergoing lower limb surgery. ${ }^{9}$ They concluded that magnesium delayed the onset of sensory and motor blocks, but prolonged the duration of spinal anesthesia. In another study conducted by Elsharnouby et al. in Cairo in 2008, intra-articular injections of bupivacaine with magnesium resulted in longer periods of analgesia (duration) when compared with the control group that received a placebo. ${ }^{10}$ Two similar studies conducted by Arcioni et al. and by ElKerdawy reported that the addition of magnesium increased the duration time of an epidural analgesia. $^{11,12}$

Narang et al. investigated the effect of magnesium in a Bier block and reported that the onset of sensory and motor analgesia was faster in the magnesium group than in the placebo group. ${ }^{13}$ There was also an increased incidence of transient pain on injection when magnesium sulfate was added to the block. These findings were in contrast to our study. Gunduz et al. reported that magnesium prolonged the duration of the supraclavicular brachial plexus block. ${ }^{5}$ Furthermore, in the study conducted by Abdelfatah and Elshaer it was shown that magnesium sulfate plus $0.5 \%$ bupivacaine in an interscalene plexus block prolongs the analgesic duration in shoulder arthroscopic surgery, which was also consistent with our study. ${ }^{14}$

One of the limitations of our study was a lack of regional anesthesia under guidance from sonography performed on the blocks. Therefore, it is recommended to perform another study to use the above technique. In addition, we recommend studying another sample size to receive higher doses of magnesium.

In the future, we recommend studying a larger sample size and follow-up with patients for the longitude duration to confirm the results of the study and to assess the long-term complications of the drugs.

\section{ACKNOWLEDGMENTS}

We gratefully acknowledge all volunteers, nurses, and doctors who were involved in this study.
Funding: No funding sources

Conflict of interest: None declared

Ethical approval: The study was approved by the Institutional

Ethics Committee

\section{REFERENCES}

1. Kroin JS, McCarthy RJ, Von Roenn N, Schwab B, Tuman KJ, Ivankovich AD. Magnesium sulfate potentiates morphine antinociception at the spinal level. Anesth Analg. 2000;90(4):913-7.

2. Mesbah Kiaee M, Safari S, Movaseghi GR, Mohaghegh Dolatabadi MR, Ghorbanlo M, Etemadi M, et al. The effect of intravenous magnesium sulfate and lidocaine in hemodynamic responses to endotracheal intubation in elective coronary artery bypass grafting: a randomized controlled clinical trial. Anesth Pain Med. 2014;4(3):e15905.

3. Choi IG, Choi YS, Kim YH, Min JH, Chae YK, Lee YK, et al. The effects of postoperative brachial plexus block using mgso (4) on the postoperative pain after upper extremity surgery. Korean J Pain. 2011;24(3):158-63.

4. Buvanendran A, McCarthy RJ, Kroin JS, Leong W, Perry P, Tuman KJ. Intrathecal magnesium prolongs fentanyl analgesia: a prospective, randomized, controlled trial. Anesth Analg. 2002;95(3):661-6.

5. Gunduz A, Bilir A, Gulec S. Magnesium added to prilocaine prolongs the duration of axillary plexus block. Reg Anesth Pain Med. 2006;31(3):233-6.

6. Apan A, Buyukkocak U, Ozcan S, Sari E, Basar H. Postoperative magnesium sulphate infusion reduces analgesic requirements in spinal anaesthesia. Eur J Anaesthesiol. 2004;21(10):766-9.

7. Dabbagh A, Elyasi H, Razavi SS, Fathi M, Rajaei S. Intravenous magnesium sulfate for post-operative pain in patients undergoing lower limb orthopedic surgery. Acta Anaesthesiol Scand. 2009;53(8):1088-91.

8. Mirkheshti A, Aryani MR, Shojaei P, Dabbagh A. The effect of adding magnesium sulfate to lidocaine compared with paracetamol in prevention of acute pain in hand surgery patients under intravenous regional anesthesia (IVRA). Int J Prev Med. 2012;3(9):616-21.

9. Ozalevli M, Cetin TO, Unlugenc H, Guler T, Isik G. The effect of adding intrathecal magnesium sulphate to bupivacaine-fentanyl spinal anaesthesia. Acta Anaesthesiol Scand. 2005;49(10):1514-9.

10. Elsharnouby NM, Eid HE, Abou Elezz NF, Moharram AN. Intraarticular injection of magnesium sulphate and/ or bupivacaine for post-operative analgesia after arthroscopic knee surgery. Anesth Analg. 2008; 106(5):1548-52.

11. Arcioni R, Palmisani S, Tigano S, Santorsola C, Sauli V, Romanò $\mathrm{S}$, et al. Combined intrathecal and epidural magnesium sulfate supplementation of spinal anesthesia to reduce post-operative analgesic requirements: a prospective, randomized, double-blind, controlled trial in patients undergoing major orthopedic surgery. Acta Anaesthesiol Scand. 2007;51(4):482-9.

12. El-Kerdawy $H$. Analgesic requirements for patients undergoing lower extremity orthopedic surgery - the effect of combined spinal and epidural magnesium. Middle East J Anaesthesiol. 2008;19(5):1013-25. 
13. Narang S, Dali JS, Agarwal M, Garg R. Evaluation of the efficacy of magnesium sulphate as an adjuvant to lignocaine for intravenous regional anaesthesia for upper limb surgery. Anaesth Intensive Care. 2008;36(6):840-4.

14. Abdelfatah AM, Elshaer AN. The effect of adding magnesium sulfate to $0.5 \%$ bupivacainein an interscalene plexus block for shoulder arthroscopic acromioplasty. AinShams J Anaesthesiol. 2014;7(1):59-64. doi: $10.5455 / 2319-2003 . i j b c p 20150429$

Cite this article as: Rao LN, Jeyalakshmi V, Nagaraju M, Anitha S. The effect of magnesium sulfate as an adjuvant to $0.5 \%$ bupivacaine on motor and sensory supraclavicular brachial plexus blockade. Int J Basic Clin Pharmacol 2015;4:317-21. 